\title{
Norm-based Abduction Process (NAP) in Developing Information Architecture
}

\author{
Chekfoung Tan ${ }^{1}$, Sara Abdaless ${ }^{2}$, Kecheng Liu ${ }^{3}$ \\ ${ }^{1}$ School of Computing and Engineering, University of West London, UK \\ chekfoung.taneuwl.ac.uk \\ ${ }^{2}$ School of Business, London South Bank University, UK \\ abdalesselsbu.ac.uk \\ ${ }^{3}$ Informatics Research Centre, University of Reading, UK \\ Wuhan College, Wuhan, China \\ kecheng.liu@henley.ac.uk
}

\begin{abstract}
Abduction is a logical reasoning process that allows the discovery and creation of new knowledge. However, the function of knowledge is not explicitly developed in the existing research on abduction. Developing information architecture is a scientific inquiry in a practical context as it engages multiple stakeholders. However, the current research in information architecture does not appear to be underpinned by sound theoretical foundations. This paper proposes a norm-based abduction process (NAP) where norms are seen as knowledge in developing information architecture. A case study of a UK hospital is used for illustration purposes. The key contribution of this paper is to incorporate norms in the existing abduction process, to assert abduction as the foundation of a logical reasoning process and to derive a theoretical proposition for information architecture.
\end{abstract}

Keywords: Abduction, Logical Reasoning, Information Architecture, Organisational Semiotics

\section{Introduction}

The term of information architecture (IA) was coined by Richard Saul Wurman back in the mid-seventies. IA is seen as a tool to gather, organise and present information that serves a purpose [1]. Research has shown that IA did not seem to have sufficient theoretical underpinnings as it is defined based on the application context [2]. For instance, IA is referred to as the external presentation of information (e.g. the websites) or the internal organisation of information (e.g. information management) [3]. Therefore, IA can be seen as a design process or a solution for a design problem [modified from 4]. Hence, there is a need to establish a theoretical proposition for the development of IA which is in relation to its nature as a design process.

Abduction is a type of logical reasoning and it plays a vital role in design process [5]. Peirce [6] defined abduction as the process of forming explanatory proposition which starts a new idea. Peirce viewed the reasoning approach as a semiosis process. 
Semiosis is a sense-making process which involves three universal categories (firstness, secondness and thirdness) which correspond to the three main reasoning approaches (abduction, deduction and induction). Being based on prior knowledge and preliminary data collection about the phenomenon, abduction is used to generate a theoretical proposition which is then explicated through deduction and empirically verified through induction [7]. However, the existing research on the abduction process does not develop the function of knowledge explicitly. For this reason, a new abduction process highlighting the importance of knowledge in the development of information architecture is introduced in this paper.

The aim of this paper is to propose a norm-based abduction process (NAP) in the development of IA. Norms are regarded as the interpretation of signs, or knowledge, which guides human behaviour and actions [8-10]. The notion of norms is employed to unambiguously elicit the function of knowledge in each stage of NAP. Norms emphasise the cumulative nature of knowledge in each stage of the scientific inquiry. NAP helps researchers to resolve the puzzlement based upon the prior knowledge and preliminary data collection. IA is seen as a design process for an observed problem; it is also an inquiry process which involves reasoning in deriving the artefacts. The reasoning process is complicated as it engages multiple human agents. NAP is therefore an abduction process that explicitly focusses on the use of knowledge in developing IA.

This paper is structured as follows: Section 2 describes the theoretical foundation of this research, Section 3 illustrates NAP, Section 4 demonstrates a practical application of NAP in developing the IA for a UK hospital. Healthcare organisations are complex and known as the world's largest and most inefficient information enterprises $[11,12]$, and Section 5 concludes the discussion of the contributions, limitations and future work on NAP as a reasoning process in developing IA.

\section{$2 \quad$ Literature Review}

\subsection{Information Architecture}

Information architecture (IA) describes the transformation of data into meaningful information for people to use [1]. IA possesses a high level map of information requirements in an organisation; it is also a design process in architecting information in order to achieve organisational benefits $[13,14]$. In this section, the theories covered for developing IA are organisational semiotics (OS) and service-oriented enterprise architecture (SOEA). OS underpins the fundamental concept of signs and norms in learning the use of information in an organisation. IA plays various roles depending on the context of application [15]. SOEA offers an architectural method for designing IA as an artefact.

OS characterises an organisation as a structure of social norms and it is seen as an information system [9]. Hence, information requirements can be deduced once the norms within an organisation are identified. Norms are developed through the practical experiences of the human agents in an organisation, thus the norms have directive and prescriptive functions on the human agent's action [16]. Organisational onion 
(OO) categorises norms of an organisation into three layers [17]: informal, formal and technical. The informal layer refers to organisational culture, customs and values which are reflected as beliefs, habits and patterns of members in the organisation. The formal layer denotes the rules and bureaucracy to perform the organisational activities. The technical layer contains technical systems which enable actions performed in the formal and informal layers. Organisational morphology (OM) further analyses the norms embedded in each layer in substantive, communication and control perspective which guide the activities performed in an organisation [18]. Substantive norms are productivity related actions. Communication norms administer activities that involve message passing from one agent to another in order to coordinate their substantive activities. Control norms reinforce the substantive and communication activities through rules and regulation.

SOEA provides a holistic information management framework for an organisation [adapted from 19,20]. SOEA is one of the approaches in designing IA. SOEA aims to leverage the strengths of service-oriented architecture in aligning various architectures derived from the enterprise architecture. The service-oriented concept emphasises on framing the business and IT capability in an organisation as a series of services. SOEA designs a language which is mutually understandable by the business and IT personnel. SOEA contains three layers: business layer, application layer and technical layer. The business layer offers services or products to customers through business components such as business processes and business actors. The application layer contains the application components which realise the business services. The technical layer offers technical components which realise the application services.

\subsection{Abduction in Design Research}

Abduction is a reasoning approach which aims to explore the data, find a pattern and suggest a plausible hypothesis [6]. The logical form of abduction is as follows: The surprising fact, $C$ is observed; but if A were true, $C$ would be a matter of course; hence, there is reason to suspect that $A$ is true. Kovács and Spens [21] and Thagard [22] propose the abduction process based on Peirce's definition on abduction. The proposed abduction process starts with the observation of a phenomenon and simultaneously triggers a process of matching prior knowledge with the observed phenomenon. Abduction is therefore a logical reasoning process. Peirce stamped the logic of reasoning as a semiosis process. Based on the semiosis process (see Figure 1), one can postulate that abduction takes the firstness as the starting point to generate new ideas. These ideas are in the form of theoretical propositions which suggest a possible explanation of a phenomenon. Abduction process eventually generates new knowledge. Deduction commences at the secondness which takes the existing theoretical propositions and applies them in a small number of individual cases. Induction departs from the thirdness and it uses the data gathered in a large scale to conduct empirical studies. The results obtained from the empirical experiments serve for generalisation of the proposition. The logic of reasoning is employed to answer the research questions which require an answer in a form of the respective conclusion [23]. 
Abduction is closely related with design science research. March [5] was the first to introduce Peirce's abduction to design. He posits "abduction is the only logical operation which introduces any new ideas; for induction does nothing but determine a value; and deduction merely evolves the necessary consequences of a pure hypothesis". Abduction is seen as a key reasoning approach in designing a solution which deals with complex problems [24]. Abduction generates better ideas over time, hence boosting creativity in problem solving [25-27]. Fischer et al. [28] propound four aspects of abduction in the design science research: 1) validity, ensures the design solution proposed by the theory works correctly, 2) utility, ascertains the design solution fulfils stakeholders' needs, 3) generality, reflects the design solution as a generic solution, and 4) innovativeness, demonstrates the new element in the design solution.

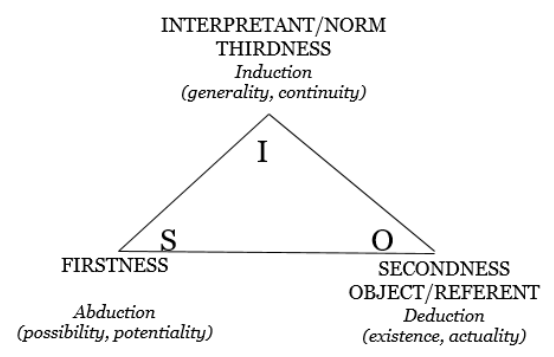

Fig. 1. Semiosis as a Logical Reasoning Process [adapted from 29,30,31,6,32,33]

\section{Norm-based Abduction Process (NAP)}

The norm-based abduction process (NAP) is a logical reasoning process that involves the use of norms (knowledge) (see Figure 2). NAP consists of interactions (inferring, resulting or matching) between three main elements which are: 1) the human agent who is always going to have some sort of prior knowledge $(A+K), 2)$ the sign which is referred to as $\mathrm{S}$ when it is representing the observed phenomenon and $\mathrm{S}+$ when it refers to the data collected about the phenomenon and, 3 ) the proposition that is referred to as $\mathrm{P}$ when it is the first set of propositions and $\mathrm{P}+$ when it is the second set of propositions after reforming the former. This relationship between $\mathrm{A}+\mathrm{K}, \mathrm{S}$ and $\mathrm{P} / \mathrm{P}+$ will vary from a stage to another in NAP. Section 4 provides the description and application of each stage of NAP.

\section{Case Study: NAP in Developing IA for a UK Hospital}

A case study has been conducted in a UK hospital in order to demonstrate NAP in the development of IA. IA is vital for healthcare organisations in providing the right information to the right hospital staff at the right time [15]. Below is the illustration of the NAP (in reference to Figure 1) in the development of IA for a UK hospital. 


\section{Stage 1: Identifying the motivation of research}

NAP starts with a puzzlement following the observation of a problem (resulted by signs $(S)$ ) by the agent. The agent here refers to the researcher. The agent is then using the prior knowledge $(A+K)$ to infer the observed problem (the $S)$. The agent noticed that there were redundancy processes in creating clinical and operational reports in the hospital (the puzzlement) and the hospital did not opt for any architectural frameworks to address the issue of information mismanagement (the $S$ ). This stage refers to the motivation of having the IA in place to better the information management practice of the hospital.

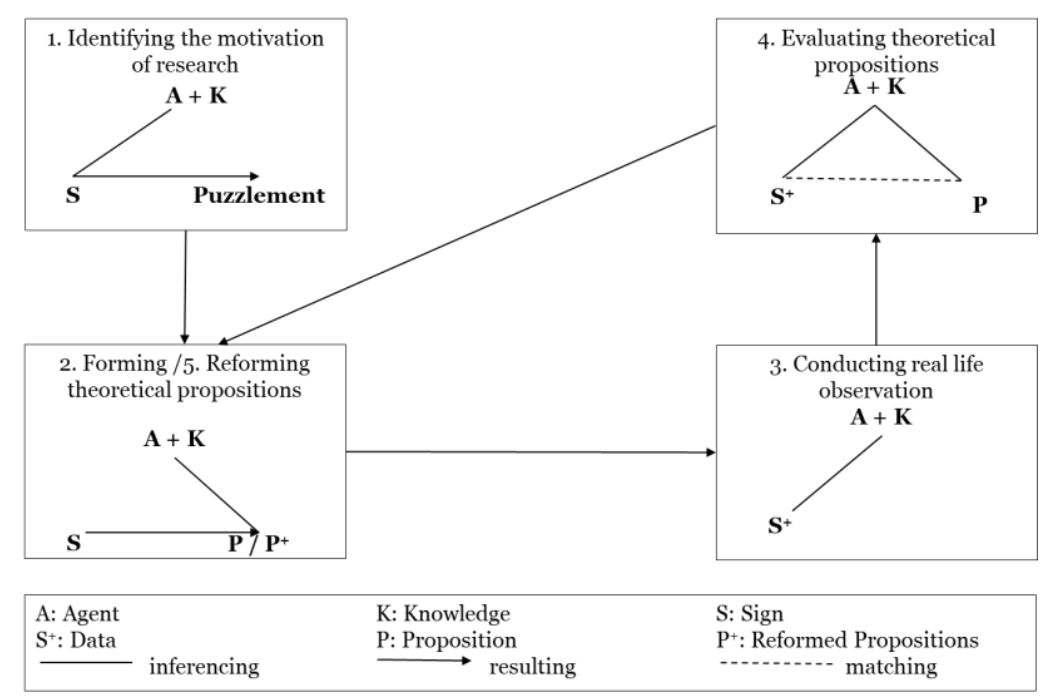

Fig. 2. Norm-based Abduction Process (NAP)

\section{Stage 2: Forming theoretical propositions}

The researcher (agent) with the prior knowledge on IA attempts to form the theoretical proposition, which is the result of the information mismanagement phenomenon (sign). In this case study, IA is meant to resolve the information mismanagement issue. Therefore, the theoretical proposition is that "IA is norm centric", whereby designing and using IA to enable effective information management. Norms, in the study of OS illustrate how the information is used by the human agents in performing certain actions in an organisation [9]. Norms therefore are adopted in the development of IA. Following $\mathrm{OO}$ and $\mathrm{OM}$ [2], Figure 3 describes the nine activity categories of norms for eliciting information requirements: organisation.informal.substantive (o.i.s), organisation.informal.message passing (o.i.m), organisation.informal.control (o.i.c), organisation.formal.substantive (o.f.s), organisation.formal.message passing (o.f.m), organisation.formal.control (o.f.c), organisation.technical.substantive (o.t.s), organisation.technical.message passing (o.t.m), and organisation.technical.control (o.t.c). 


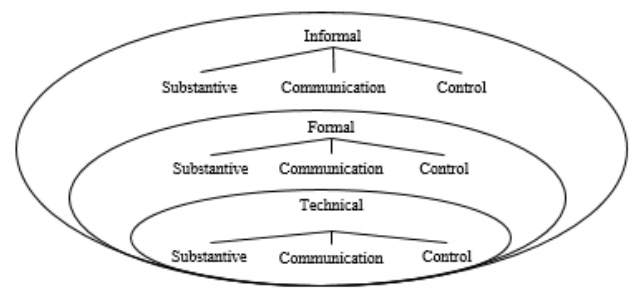

Fig. 3. Norms and Activities

Based on this activity categorisation, information requirements are elicited in six dimensions per each activity. The dimensions are: Who are using the information, What is the content of the information, How information is represented, Where information is stored, When the information is needed and Why the information is needed in that activity. Figure 4 depicts the example of information requirements from one of the organisational.formal.substantive (o.f.s) activities. SOEA was employed to model the actual IA for practical use in the final stage.

\begin{tabular}{|l|l|l|l|l|l|}
\hline When & Who & What & How & Where & Why \\
\hline $\begin{array}{l}\text { Check-in } \\
\text { patients }\end{array}$ & $\begin{array}{l}\text { Receptionist, } \\
\text { Clinician }\end{array}$ & $\begin{array}{l}\text { Appointment details such as } \\
\text { patient demographic information, } \\
\text { appointment type, purpose of } \\
\text { appointment, date and time, } \\
\text { clinician details }\end{array}$ & $\begin{array}{l}\text { Format is in the } \\
\text { electronic } \\
\text { patient record }\end{array}$ & $\begin{array}{l}\text { Hospital } \\
\text { correspondence } \\
\text { letter, Electronic } \\
\text { patient record }\end{array}$ & $\begin{array}{l}\text { Ensure clinician is } \\
\text { aware of this } \\
\text { patient's appointment } \\
\text { and health condition }\end{array}$ \\
\hline
\end{tabular}

Fig. 4. Information Requirements of the 'check-in patient' activity

\section{Stage 3: Conducting real life observation}

In this case study, the researcher (agent) with prior knowledge $(A+K)$ on IA collects data in order to understand the phenomenon of information mismanagement. Data $\left(S^{+}\right)$were collected through observations in two sites: 1) an outpatient clinic for gathering the information requirements by using the template as in Figure 2 and 3), and 2) information services department in order to understand how information is processed at the backend for reporting purpose. The secondary data were collected through various documents produced by the hospital. The standard operating procedures (SOPs) were the key documentation for understanding the business activities (formal norms) and how these business activities were executed through IT systems (technical norms). In addition, the outpatient commissioning data sets (CDS) from Hospital Episode Statistics (HES) [34] were adapted to detail the information elements which construct the IA.

\section{Stage 4: Evaluating theoretical propositions}

The researcher (agent) with prior knowledge $(A+\mathrm{K})$ on information architecture and experience working in the hospital is inferred by the data collected $\left(S^{+}\right)$which will direct the method for data analysis. The result of the data analysis is then used to verify or refute the theoretical proposition $(P)$ formed in stage 2 , which "information 
architecture is norm centric". In this case study, thematic analysis was used to analyse the collected data in the outpatient clinic in stage 3. SOEA was adopted to encapsulate the collected information requirements into services. These services informed the information elements that supported the activities. As a result, there were two types of services: clinical and administrative services. The clinical services were: consultation (non-theatre procedure, elective surgical procedure), triage, advice and guidance, diagnosis (pathology, radiology), discharge and prescription. The administrative services were patient administration, referral, appointment and scheduling, payment, and information management. Descriptive analysis was adopted to analyse the collected data in the information service department. It narrated the information management processes (information collection, processing and dissemination) in the hospital. Document analysis was conducted for analysing the SOPs and CDS. This was used to detail the information elements that supported the services. Figure 5 illustrated one of the information elements for the 'radiologic diagnosis' activity. The information architecture was a collection of information elements which can be modelled with SOEA principles. IA shows how information was collected in the business layer and processed through the application and infrastructure layer. The theoretical proposition was preliminarily evaluated through gathering feedback from the subject matter experts in the hospital. According to the subject matter experts, the proposed IA covered the information requirements for a whole department instead of a single information system view and demonstrates how information was facilitated from the business environment to the technical systems. Moreover, they found that the proposed IA had a positive contribution to addresses the issue of information mismanagement in the hospital.

\begin{tabular}{|ll|}
\hline Radiologic Diagnosis & \\
\hline Radiology Investigation Plan Identifier & Radiology Procedure Requested Date \\
Diagnosis Scheme in Use & Radiology Procedure Priority \\
Primary Diagnosis & Radiology Latest Date \\
Present on Admission Indicator (Primary Diagnosis) & Radiology Procedure Earliest Date \\
Secondary Diagnosis & Radiology Investigation Status Reason \\
Radiology Service Report Urgency & Radiology Investigation Prev Indicator \\
Radiology Service Order Issue Time & Radiology Investigation Plan Status \\
Radiology Service Order Issue Date & Radiology Appointment Required \\
Radiology Procedure Requested Time & \\
\hline
\end{tabular}

Fig. 5. Information Element

\section{Stage 5: Reforming theoretical propositions}

The researcher (agent) concludes the theoretical proposition $(P)$ formed in stage 2 which is resulted by the information mismanagement phenomenon (sign) with the prior knowledge on information architecture and new knowledge gained from the analysed data in stage 4 . In this case study, the researcher partially accepted the theoretical proposition as the evaluation result showed that the proposed information architecture in stage 2 contributes to a better information management. This case study demonstrated the initial version of the information architecture for the hospital. A new theoretical proposition (proposition ${ }^{+}$) in stage 2 will be triggered if the proposed in- 
formation architecture is no longer serving the purpose. This in turn launches the second cycle of NAP.

\section{$5 \quad$ Discussions and Conclusion}

This paper illustrates the norm-based abduction process (NAP) in the development of information architecture. The five stages in NAP involve prior knowledge of the human agents to perform the relative actions within the stages. Abduction is a logical reasoning that plays a role in design research and IA is seen as a design process. NAP is therefore applied in developing IA. A case study is conducted in a UK hospital to demonstrate the application of NAP in developing IA. IA is vital for healthcare organisations in ensuring the right information is provisioned to the right hospital staff at the right time. The contributions of this paper are twofold: 1) extending the existing abduction process by incorporating norms, and 2) deriving a theoretical proposition for information architecture.

The first contribution of this paper is that NAP incorporates norms in the existing abduction process such as [22] and [21]. Norms are regarded to be knowledge as they are derived from the interpretation of signs by the human agents $[8,10]$. NAP scrutinises the use of norms (interpretation of signs) in each stage of the abduction process in order to highlight the function of knowledge (see Section 3 and 4). NAP fulfils the scientific inquiry process suggested by Kuhn [35] in leading to new knowledge in the form of a new proposition, which is the result of the observation of a phenomenon. In addition, NAP adopts Popper's [36] refutation approach, where the formed proposition can be refuted by the observed facts. This encourages the agent to continue the inquiry process in order to find the best proposition resulted by the phenomenon. NAP guides the design process in producing the IA and provides a specification of the IA as an artefact. The abduction appraoch in NAP where knowledge is imparted in each stage of the process helps in forming the theoretical proposition for the development of IA. In a practical perspective, the abduction approach in NAP helps information professionals to apply a new idea in boosting the informatics creativity for finding ways to progress from being "data rich and discovery poor to a state of information wealth" [37]. NAP is iterative, and the number of NAP cycles is depending on the subjective view of the agent.

There are two limitations identified in this paper. The first limitation is that it is hard to determine when the iteration of NAP stops. It is assumed that the agent will stop when he or she believes that a best proposition has been achieved. In addition, the second limitation is that there is only one cycle of NAP presented in the case study of developing the IA. There is a need for the agent to conduct multiple cycles of NAP in order to reform the theoretical proposition until it explains or resolves, in this instance, the information mismanagement phenomenon.

As for the future work, the impact of abduction on a scientific inquiry will be explored in depth especially with the purpose of discovering and creating knowledge. In this paper, NAP consists of five stages and regards norms as a mean to understand the function of knowledge. The norms specification from OS will be incorporated in each 
stage of NAP for knowledge profiling at the individual level by incorporating perceptual, cognitive, evaluative, denotative and behavioural norms. In addition, NAP will be developed as a research methodology which will enable the researcher to make more informed decision on how IA should be designed. From the practical perspective, more cycles of the NAP are going to be conducted in the industry with practitioners such as information managers. This approach aims to finalise the best proposition in the process of developing IA. In addition, this will increase the validity, utility, generality, and innovativeness of the specification of the IA as an artefact.

\section{References}

1. Dillon, A., Turnbull, D.: Information Architecture. In: Encyclopedia of Library and Information Science. New York: Marcel Dekker, (2005)

2. Tan, C., Liu, K., White, E.: Information Architecture for Healthcare Organizations: the case of a NHS Hospital in UK Paper presented at the Thirty Fourth International Conference on Information Systems (ICIS2013), Milan, Italy,

3. Bryant, A., Maes, R.: The Role of the Information Architect: Conquering CognitiveParochialism. All Sprouts Content Paper 96 (2008).

4. Haverty, M.: Information architecture without internal theory: An inductive design process. Journal of the American society for information science and technology 53(10), 839-845 (2002).

5. March, L.: The Logic of Design. In: Cross, N. (ed.) Developments in Design Methodology. pp. 265-276. John Wiley \& Sons, Chichester (1984)

6. Peirce, C.S.: Collected Papers of Charles Sanders Peirce: Pragmaticisms and Pragnoaticism, Scientific Metaphysics, vol. 5-6. Belknap Press, MA, US (1935)

7. Liu, K., Li, W.: Organisational semiotics and business informatics. Routledge, Abingdon, UK (2015)

8. Stamper, R.: Information Systems as a Social Science: An Alternative to the FRISCO Formalism. In: Information System Concepts: an Integrated Discipline Emerging. pp. 1-51. Springer, (2000)

9. Stamper, R., Liu, K., Hafkamp, M., Ades, Y.: Understanding the roles of signs and norms in organizations-a semiotic approach to information systems design. Behaviour \& Information Technology 19(1), 15-27 (2000).

10. Braf, E.: Knowledge or Information: : What makes the difference? In: Liu, K., J.Clarke, R., Andersen, P.B., K.Stamper, R., Abou-Zeid, E.-S. (eds.) Organizational Semiotics: Evolving a science of information systems. pp. 71-90. Kluwer Academic Publishers, Massachusetts (2002)

11. Hillestad, R., Bigelow, J., Bower, A., Girosi, F., Meili, R., Scoville, R., Taylor, R.: Can electronic medical record systems transform health care? Potential health benefits, savings, and costs. Health Affairs 24(5), 1103-1117 (2005).

12. Martin, A., Dmitriev, D., Akeroyd, J.: A resurgence of interest in Information Architecture. International Journal of Information Management 30(1), 6-12 (2010).

13. Brancheau, J.C., Wetherbe, J.C.: Information architectures: methods and practice. Information Processing \& Management 22(6), 453-463 (1986).

14. Evernden, R., Evernden, E.: Information first: integrating knowledge and information architecture for business advantage. Elsevier Butterworth-Heinemann, Oxford, UK (2003)

15. Tan, C., Liu, K.: An organisational semiotics inspired information architecture: pervasive healthcare as a case study. Paper presented at the 14th International Conference on Informatics and Semiotics in Organisation (ICISO), Stockholm, Sweden, 25 -27 March 2013 
16. Liu, K.: Semiotics in information systems engineering. Cambridge University Press, Cambridge, UK (2000)

17. Stamper, R.: Linguistic Instruments in Knowledge Engineering. Riet, RP; Meersman, RA Elsevier Science Inc., New York, NY, USA, ch. Language and computer in organized behavior (1992)

18. Stamper, R., Liu, K., Huang, K.: Organisational morphology in re-engineering. In: 1994, pp. $729-737$

19. Steen, M.W., Strating, P., Lankhorst, M.M., ter Doest, H., Iacob, M.-E.: Service-Oriented Enterprise Architecture. In: Stojanović, Z., Dahanayake, A. (eds.) Service-oriented Software System Engineering: Challenges and Practices. pp. 132-154. Idea Group Publishing, Hershey (2005)

20. Van den Hoven, J.: Data architecture: blueprints for data. Information systems management 19(4), 90-92 (2003).

21. Kovács, G., Spens, K.M.: Abductive reasoning in logistics research. International Journal of Physical Distribution \& Logistics Management 35(2), 132-144 (2005).

22. Thagard, P.: Abductive inference: From philosophical analysis to neural mechanisms. In: Feeney, A., Heit, E. (eds.) Inductive reasoning: Experimental, developmental, and computational approaches. pp. 226-247. Cambridge University Press, Cambridge (2007)

23. Minnameier, G.: The logicality of abduction, deduction, and induction. In: Ideas in action: Proceedings of the Applying Peirce Conference 2010, pp. 239-251. Nordic Pragmatism Network Helsinki

24. Dorst, K.: The core of 'design thinking'and its application. Design Studies 32(6), 521-532 (2011).

25. Gregory, R., Muntermann, J.: Theorizing in design science research: inductive versus deductive approaches. Paper presented at the Thirty Second International Conference on Information Systems (ICIS 2011), Shanghai,

26. Dubois, A., Gadde, L.-E.: Systematic combining: an abductive approach to case research. Journal of business research 55(7), 553-560 (2002).

27. Pauwels, P., De Meyer, R., Van Campenhout, J.: Design thinking support: information systems versus reasoning. Design Issues 29(2), 42-59 (2013).

28. Fischer, C., Gregor, S., Aier, S.: Forms of discovery for design knowledge. Paper presented at the 20th European Conference on Information Systems (ECIS2012), Barcelona, Spain,

29. Yu, C.H.: Abduction? Deduction? Induction? Is There a Logic of Exploratory Data Analysis? Paper presented at the Annual Meeting of the American Educational Research Association, NewOrleans, LA,

30. Wirth, U.: What is abductive inference? In: Bouissac, P. (ed.) Encyclopedia of semiotics. pp. 1-3. Oxford University Press, Oxford (1998)

31. Staat, W.: On abduction, deduction, induction and the categories. Transactions of the Charles S. Peirce Society 29(2), 225-237 (1993).

32. Everaert-Desmedt, N.: Peirce's semiotics. http://www.signosemio.com/peirce/semiotics.asp (2010). Accessed 01-April-2014

33. Burks, A.W.: Peirce's theory of abduction. Philosophy of science 13(4), 301-306 (1946).

34. HSCIS: Hospital Episode Statistics. http://www.hscic.gov.uk/hes (2013). Accessed 01April-14

35. Kuhn, T.S.: The structure of scientific revolutions, vol. 2. The University of Chicago Press, Chicago (1962)

36. Popper, K.R.: Conjectures and refutations, vol. 192. Routledge and Kegan Paul, London (1963)

37. Ross, J.M.: Informatics creativity: a role for abductive reasoning? Communications of the ACM 53(2), 144-148 (2010). 